\title{
Communication in Nuclear Emergency Preparedness: A Closer Look at Information Reception
}

\author{
Tanja Perko, ${ }^{1, *}$ Baldwin van Gorp, ${ }^{2}$ Catrinel Turcanu, ${ }^{1}$ Peter Thijssen, ${ }^{3}$ and Benny Carle ${ }^{4}$
}

\begin{abstract}
Preparedness of the general population plays a key role in the effective implementation of protective actions in case of a nuclear emergency (e.g., evacuation or intake of iodine tablets). In this context, a good communication of emergency management actors with the public along the entire cycle of preparedness-response-recovery is of paramount importance. This article aims at providing a better understanding of the way people process communicated messages and the factors that may influence how they do this. In particular, it investigates information reception as part of the information processing in precrisis communication. As a case study, the precrisis communication context was chosen, as it has been tackled to a lesser extent in the literature. The empirical data used for this study originated from a large-scale opinion survey in Belgium. One topic in this survey addressed the information campaign for the distribution of iodine tablets, in the context of preparedness for nuclear emergencies. The findings of this study demonstrate that systematic predictors have a stronger influence on information reception, as compared to heuristic predictors. The latter are only to a minor extent involved in the reception of emergency preparedness information. The hypothesized pattern - that more specific knowledge about the field relates to a higher reception of information-was confirmed for precrisis communication. Contrary to expectations, results showed that people with a high perception of radiation risks were less attentive to information about protective actions. People with little confidence in authorities were also more likely to have a low reception of information.
\end{abstract}

KEY WORDS: Information processing; nuclear emergency; reception; risk communication; systematic and heuristic

\section{INTRODUCTION}

Whether a risk information campaign is intensive or not, there will always be people who do not get the

\footnotetext{
${ }^{1}$ Belgian Nuclear Research Center, SCK.CEN, Society and Policy Support, Boeretang 200, Mol 2400, Belgium.

${ }^{2}$ Katholieke Universiteit Leuven, Centre of Media Culture and Communication Technology, Parkstraat 45, Leuven 3000, Belgium.

${ }^{3}$ University of Antwerp, Political and Social Sciences, Sint Jacobstraat 2, Antwerp 2000, Belgium.

${ }^{4}$ Belgian Nuclear Research Center, SCK.CEN, Internal Service for Preventions and Protection at Work, Boeretang 200, Mol 2400, Belgium.

*Address correspondence to Tanja Perko, Belgian Nuclear Research Center, SCK CEN, Society and Policy Support, Boeretang 200, Mol 2400, Belgium; tperko@sckcen.be.
}

information. Who are these people and what influences their resistance to information? Such issues are essential in the context of preparedness for nuclear emergencies, since the effectiveness of protective actions depends largely on the population's response to the advice from the authorities or other emergency actors. Our article addresses precrisis risk communication related to the campaign for distribution of iodine tablets to the people living in the vicinity of nuclear installations in Belgium. ${ }^{(1)}$

An average individual in today's society is exposed to a large amount of risk-related information, definitely much more than one can absorb. ${ }^{(2)}$ If the information does not carry certain symbolic cues (stimulus for processing, e.g., visuals or noise) or does not match the receiver's interests, it is 
likely that it will not grab the receiver's attention or that $\mathrm{s} / \mathrm{he}$ will not involve him/herself in the communication. ${ }^{(3-7)}$ Therefore, in precrisis risk communication, the primary goal is to make the message interesting enough to attract the attention of the general population. In this way, the message will stay in people's memory for as long as it is needed to recall the message, for example, in case of a real emergency, and, finally, to make a decision about a given risk. This substantiates the need for studying the reception stage of risk information processing.

Information processing consists of two main processes: reception and acceptance. ${ }^{(8)}$ The reception of information refers specifically to the extent to which an individual pays attention to and understands the information encountered. According to the definition of Price and Zaller, ${ }^{(9: 134)}$ reception entails a sequence of information processing steps: (1) attending to the information, (2) comprehending it, and (3) retaining it. This is mostly a cognitive process that involves individuals selectively reprocessing and storing information. Acceptance of information ${ }^{(8)}$ refers to the "probability of agreeing with the information." Although the literature has seen a growing interest in information processing as a whole, ${ }^{(7,10-12)}$ there has been little empirical research testing the reception part of information processing. Moreover, so far reception has only been studied separately in the context of political communication. ${ }^{(8,13,14)}$ In this article, we extend the study of reception-as a distinctive part of information processing - to the precrisis risk communication in the context of nuclear emergency management.

Precrisis communication is essential in emergency preparedness, which, in turn, is the key to an effective management of nuclear emergencies. ${ }^{(15)}$ Knowledge about the nuclear domain is rather limited ${ }^{(16,17)}$ in the general population, who does not have any direct contact with nuclear risks, but mainly learns about it through the media and politicians. ${ }^{(18)}$ Emergency management actors (e.g., authorities or operators) have thus a challenging task to communicate with the public about protective actions in the preparedness phase of emergency management, when people are in general less attentive toward the issue. The context of precrisis communication is comparable to the context of political communication, since the risk (e.g., a nuclear accident) is typically intensively communicated, but the attentiveness and familiarity with the messages among the population is usually low. Moreover, risk-related discussions appear frequently in political agendas; therefore, politicians often draw the public attention to a particular risk. ${ }^{(19,20)}$

The aim of this study was to investigate predictors in audience reception of precrisis risk communication and to empirically test whether the variables that have been traditionally used in risk research have a distinct effect in the reception stage of information processing. In Zaller's receiveaccept-sample (RAS) model, education and level of specific knowledge are suggested as the major predictors of information reception. ${ }^{(8)}$ These two predictors can be linked ${ }^{(8,10)}$ to systematic information processing, which is effort-intensive and deep. Petty and Cacioppo ${ }^{(10)}$ showed that low prior knowledge leads to heuristic information processing (peripheral route), while high prior knowledge leads to systematic processing (central route). In addition, risk research theory, as developed by Griffin, ${ }^{(21)}$ Slovic, ${ }^{(22)}$ Sjöberg, ${ }^{(23)}$ Renn, ${ }^{(2)}$ and others, has emphasized the importance of heuristic predictors (e.g., trust or risk perception) that might play a role in the reception of information related to potential risks. For instance, the risk information seeking and processing model (RISP), developed by Griffin, ${ }^{(11)}$ stresses the importance of affective response to risk (e.g., worry, anxiety, fear) as a predictor of information seeking. Heuristic information processing stresses the mental shortcuts individuals use when they have to deal with information. Before a crisis, the motivation for information processing is lower, since the information may or may not be useful sometime in the future; hence it seems logical that people revert to shortcuts.

However, risk theory usually does not make an explicit distinction between reception and acceptance of information. In this respect, it is possible that predictors of systematic processing are more important for the reception of precrisis information, while predictors of heuristic processing play the dominant role for the acceptance of precrisis information. To test this, we construct an explanatory model that comprises both heuristic and systematic predictors. Based on an extensive review of the literature, we propose a set of predictors that may influence people's attention to precrisis information: education and specific knowledge as systematic predictors and hazard experience, confidence, risk perception, and fear as heuristic predictors. Based on these predictors and patterns, we subsequently sought to identify 
subgroups of receivers expected to be particularly (in)attentive to communication about emergencies.

\section{THEORETICAL CONCEPTS}

Most information processing models describe reception as a result of attention, ability, and motivation. ${ }^{(4,7,8,24,27-29)}$ The first, attention, refers to signals for getting the message out of the environment and starting the information processing. The second, ability, involves the physical capacity of the receiver to follow the information without any distractions. Finally, motivation is considered as the willingness and interest of the receiver to process information or, at a later stage, to actively get involved in the communication. A comparison of the three information processing models employed in this study with respect to basic reception elements is presented in Table I.

As seen in Table I, in the RAS model for systematic information processing, motivation, attention, and ability are assumed to depend on the cognitive engagement with the communicated subject. According to Zaller: "The greater a person's level of cognitive engagement with an issue, the more likely he or she is to be exposed to and comprehend - in a word, to receive messages concerning that issue." (8:42) Zaller identifies two possible cognitive engagement characteristics of a message: intensity and familiarity. The weaker the intensity of the message and the receiver's familiarity with it, the stronger the effect of cognitive engagement is. Zaller's RAS model suggests that reception is mainly influenced by specific factual knowledge, but that it can also be affected by the level of participation of the receiver, his/her interest in the issue, and the media use..$^{(8: 333-339)}$ Empirical tests for these claims have been recently done by Dobrzynska and Blais. ${ }^{(13)}$ Similar to Zaller, the authors observed that people with greater specific knowledge are more likely to receive messages. In contrast, the research by Dalton et al. ${ }^{(14)}$ suggests that the reception of messages is not most accurate among the most knowledgeable people. In their study, predictors such as education, self-reported rates of media use, and prior levels of specific knowledge were tested for political messages. ${ }^{(8,30)}$ Based on these findings, education and specific knowledge were tested in the present research as predictors for the reception of risk messages.

The RISP model developed by Griffin et al. ${ }^{(21)}$ suggests that motivation is influenced by information sufficiency: affective response to a risk (e.g., worry, anger) and informational subjective norms (e.g., desire for information); the more worried or anxious people feel toward the risk issue, the more likely they are to seek information regarding the topic. In this model, ability reflects one's perceived capacity to perform the information processing steps and the nonroutine gathering of information (e.g., additional effort to get the information).

Finally, in the heuristic or peripheral processing mode as described in the elaboration likelihood model (ELM) of Petty and Cacioppo, ${ }^{(10)}$ motivation is believed to depend on three factors: the personal relevance of the risk information, the need for cognition, and personal responsibility. The ability to process the information depends, among other things, on distraction, repetition, prior knowledge, and message comprehensibility.

Since risk communication is often related to heuristic information processing, ${ }^{(31,32)}$ we also tested predictors that may stimulate heuristic information processing for reception: hazard experience, ${ }^{(7)}$ confidence, ${ }^{(10)}$ risk perception, and affective response. ${ }^{(21)}$ The first predictor, hazard experience, has been used as a measurement of heuristic processing by Trumbo. ${ }^{(7: 374)}$ He suggested that individuals are more likely to make a quick, effortless judgment based on their existing understanding and past experiences. The second one, social and institutional trust, has been demonstrated to serve as a cognitive heuristic for the individual by, for example, Earle, ${ }^{(33)}$ Freudenburg, ${ }^{(34)}$ Kasperson, ${ }^{(35)}$ Renn, ${ }^{(2)}$ Slovic, ${ }^{(36)}$ Siegrist et al.,${ }^{(37)}$ and others. More evidence that risk perception is related to heuristic processing comes from the "risk-as-a-feeling" theory, ${ }^{(38)}$ which suggests that people respond to risk based on direct emotional influence. Reliance on feelings has been called the "affect heuristic" by Slovic et al., (22) who explained that individuals' risk perception is also based on what individuals feel about the risk and not only on what they know about it. Finally, fear as an affective response to the risk is assumed to affect the intensity of information seeking, and studies in the literature suggest that it may stimulate either systematic or heuristic processing. Negative emotions stimulate the systematic mode according to Bohner et al. ${ }^{(39)}$ However, extremely negative emotions such as strong fear stimulate heuristic processing. ${ }^{(40)}$

\subsection{Hypotheses}

In the study by Griffin et al., ${ }^{(21,41)}$ education was indicated as an important predictor of an individual's 
Table I. Information Reception in Different Models: Attention, Ability, and Motivation

\begin{tabular}{|c|c|c|c|}
\hline Model & $\begin{array}{l}\text { Receive, Accept, } \\
\text { Sample Model }\end{array}$ & $\begin{array}{c}\text { Elaboration } \\
\text { Likelihood Model }\end{array}$ & $\begin{array}{l}\text { Risk Information Seeking } \\
\text { and Processing Model }\end{array}$ \\
\hline $\begin{array}{l}\text { Information processing } \\
\text { mode }\end{array}$ & $\begin{array}{l}\text { Systematic approach (also } \\
\text { called analytical, central, } \\
\text { primary, or memory-based } \\
\text { processing) }\end{array}$ & $\begin{array}{l}\text { Two exclusive modes: first } \\
\text { named peripheral, heuristic, } \\
\text { or on-line processing and } \\
\text { second mode named } \\
\text { systematic or central }\end{array}$ & $\begin{array}{l}\text { Systematic-heuristic: modes } \\
\text { can be simultaneously } \\
\text { exchanged }\end{array}$ \\
\hline $\begin{array}{l}\text { Factors influencing } \\
\text { attention }\end{array}$ & $\begin{array}{l}\text { Awareness, prior specific } \\
\text { knowledge, media use, } \\
\text { education }\end{array}$ & $\begin{array}{l}\text { Heuristic: trust, impression, } \\
\text { stereotype, moral } \\
\text { evaluation, number of } \\
\text { arguments, emotions } \\
\text { Systematic: strong arguments, } \\
\text { engagement }\end{array}$ & $\begin{array}{l}\text { Exposure, respondent's } \\
\text { self-reported elaboration of } \\
\text { the messages }\end{array}$ \\
\hline Factors influencing ability & Cognitive engagement & $\begin{array}{l}\text { Notion of capacity: distraction, } \\
\text { repetition, prior knowledge, } \\
\text { message comprehensibility }\end{array}$ & $\begin{array}{l}\text { Perceived information } \\
\text { gathering capacity: ability } \\
\text { and nonroutine gathering }\end{array}$ \\
\hline $\begin{array}{l}\text { Factors influencing } \\
\text { motivation }\end{array}$ & $\begin{array}{l}\text { Intensity, familiarity of } \\
\text { message }\end{array}$ & $\begin{array}{l}\text { Personal relevance, need for } \\
\text { cognition, personal } \\
\text { responsibility }\end{array}$ & $\begin{array}{l}\text { Information sufficiency: } \\
\text { affective response to a risk } \\
\text { (e.g., worry, anger), } \\
\text { informational subjective } \\
\text { norms, and hazard } \\
\text { characteristics }\end{array}$ \\
\hline
\end{tabular}

ability to seek, process, and retain risk information. They suggest that people with a higher level of education are more likely to process the information and make a judgment afterwards. In the study by Price et al., ${ }^{(42)}$ age and gender did not influence reception, whereas education was recognized as a rather weak predictor for the reception of political information. ${ }^{(8)}$ Due to these different findings, we tested education as a possible predictor for the reception of nuclear emergency messages; our first hypothesis was formulated as follows:

$\mathrm{H} 1$ : The reception of precrisis messages is more accurate among people with a higher education level than among people with lower education.

According to the RAS model, specific knowledge is the most powerful predictor for the reception part of information processing. ${ }^{(8,13,42)}$ In the context of reception research, specific knowledge can also be seen as prior knowledge. In other words, people who are well informed about a certain specific issue receive more information about the communicated issue than people who are not knowledgeable. Therefore, the next hypothesis was formulated as follows:

H2: People with more specific knowledge about nuclear topics are more likely to receive nuclear emergency messages related to preparedness for nuclear accidents than people with less knowledge.

People tend to apply past experience as an initial steer of judgment. Grunig ${ }^{(43)}$ claims that past experience serves the individual as a guide for deciding how to think, behave, or react in a new situation. In addition, Johnson and Tversky ${ }^{(44)}$ discovered that an individual's experience with one risk can indeed determine his/her responses to other risks.

In our research, we tested the experience in the radiological/nuclear field as a predictor for the reception of nuclear emergency information. We expected that having direct or indirect personal experiences, for instance, having visited a nuclear installation, would largely contribute to recalling communication messages. Therefore, the third hypothesis was the following:

H3: People with hazard experience are more likely to receive emergency messages related to preparedness for nuclear accidents than people without this experience.

Despite ample research on the "trust-risk" relation, the question of whether trust influences a person's reception of certain precrisis communication messages has not been tackled. Trust is very often emphasized ${ }^{(45)}$ as an explanation of risk perception and risk tolerance. The components of trust are 


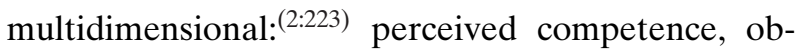
jectivity, fairness, consistency, sincerity, faith, and empathy. Earlier research has identified trust as one of the key indicators for the acceptance of nuclear risks. $^{(46-48)}$ In our study, we explored the relation between trust (expressed as confidence in the authorities) and the reception of emergency preparedness messages. However, Earle and Siegrist ${ }^{(49)}$ suggest in their trust, confidence, cooperation model that the antecedents of trust are indicated by moralityrelevant information (more heuristically driven) and the antecedents of confidence are indicated by performance-relevant information (more knowledge or experience driven). We started from the finding that with the increasing complexity of technological innovations, people find themselves in a position of not knowing much about highly complex and potentially dangerous technologies. ${ }^{(34,50)}$ People must therefore rely on their own judgments about whom to trust or what activities to trust. ${ }^{(49)}$ The fourth hypothesis was formulated as follows:

H4: People with more confidence in authorities for the actions undertaken to protect the population against radiation risks receive fewer messages related to preparedness for nuclear accidents in comparison with people with less confidence.

A considerable amount of research on risk perception has been published and a variety of theoretical perspectives exist, including cultural, ${ }^{(51)}$ sociological $^{(19)}$ and psychological ${ }^{(52)}$ ones. Risk perception is recognized as an essential social and psychological phenomenon, influencing and driving decision making at various levels, from individual to societal decision making. ${ }^{(2,19,23)}$ In all these studies, risk perception is used as a dependent variable, while in our research it is employed as an independent variable. For example, research on risk information by Griffin et al. ${ }^{(53)}$ established that response to a risk could be directly related to a person's information seeking. Since a person's high-risk perception could lead to a higher level of cognitive engagement with a hazard, we hypothesized that a person with highrisk perception would be more likely to receive emergency preparedness messages:

H5: Recipients with higher perception of nuclear risks will receive more nuclear emergency messages than people with lower perception of nuclear risks.
Fear is recognized as an affective response to a risk by Griffin et al. ${ }^{(21)}$ as a stimulator of risk information seeking. It is a strong emotional reaction that influences information processing. ${ }^{(39)}$ Huurne et al., too, found that "emotional reactions to risk are among the set of strongest predictors of individuals' risk information seeking behavior." (12:231) In the literature, the influence of emotions such as fear, worry, or anger on information processing is mainly studied with respect to complete information processing. ${ }^{(54)}$ However, the influence of strong emotions on the separate stages of information processing, for instance, reception, is a relatively unexamined area. Therefore, we formulated a sixth hypothesis:

H6: People who are more afraid of nuclear accidents will receive more nuclear emergency messages than recipients who are less afraid.

Finally, a model including the predictors addressed in the six hypotheses formulated above will help identifying if systematic predictors (see $\mathrm{H} 1$ and $\mathrm{H} 2$ ) have a stronger influence on information reception, as compared to heuristic predictors (H3-H6).

\section{METHOD}

\subsection{Description of Precrisis Communication as Part of Emergency Preparedness: The Iodine Distribution Campaign}

The six research hypotheses were examined in the context of an iodine tablets distribution campaign in Belgium. ${ }^{5}$ Distribution of stable iodine is one of the possible ways to protect the population in case of an accidental radioactive release. ${ }^{(55)}$ In Belgium, such campaigns were conducted prior to this study in 1999 and 2002. A next information campaign and distribution of the stable iodine tablets took place in 2011. The present study was conducted in 2009 as a part of a broader study on nuclear emergency preparedness.

In relation to the communication means used in the Belgian campaigns, we can make a

\footnotetext{
${ }^{5}$ Depending upon the severity of accidental release of radioactivity into the environment, a number of protective measures are considered to avoid public exposure to ionizing radiation. Besides the administration of stable iodine, other means such as sheltering, evacuation, or a change of diet can be recommended.
} 
distinction between, on the one hand, the intensive communication to the people living in the vicinity of the nuclear installations and, on the other hand, the less intensive communication to the general population in Belgium. The target population for the intensive communication campaign was the inhabitants of the Belgian municipalities located within a certain radius $(10 \mathrm{~km}$ in 1999 and $20 \mathrm{~km}$ in 2002 and 2011) from Belgian or near-border nuclear sites. This population is represented by 207 respondents in our sample, while the target population of the broader campaign is represented by 824 respondents in our sample.

The broader information campaign (for the whole of Belgium) communicated information about (1) the nuclear installations, (2) protective actions in case of a nuclear accident, (3) general information about radioactivity, and (4) the distribution and use of the stable iodine tablets. Between 2002 and 2009 , the topic of stable iodine tablets reappeared in the national media due to the radiological incident in Fleurus (Belgium) in 2008, although the intake of the tablets was not advised. One year later, stories on expired tablets caught the media's attention and triggered elite discourse on a national level, among, for instance, party members, local politicians, and pressure groups. In response, the Federal Crisis Centre released information about the possible effects of consuming the tablets on its website and sent this information to local authorities. ${ }^{(56)}$ Consequently, the negative press subsided, and the local and national media started to frame the issue more neutrally. The last information before the collection of the empirical data used in this research started was published at the beginning of 2009 by the Federal Crisis Centre and taken over by mass media approximately two months before the field work. The most recent distribution of stable iodine tablets took place in 2011, but it will not be addressed here.

The communication tools used in the campaigns were personal letters, meetings with the local communities, leaflets, advertisements published on $\mathrm{TV}$, radio, and in newspapers, press conferences, Internet pages, posters, and participation of experts at informative meetings, for example, in schools.

Based on the context and objectives of the campaign, the intensity of the communication and the tools used, we assume that the campaign for preventive distribution of iodine tablets satisfies the RAS model's conditions to test the predictors
Table II. Sociodemographic Characteristics of the Sample

\begin{tabular}{|c|c|c|c|}
\hline Variable & & $\begin{array}{c}\text { Belgian } \\
\text { Population (\%) }\end{array}$ & $\begin{array}{c}\text { Survey } \\
\text { Sample }(N= \\
1,031)(\%)\end{array}$ \\
\hline \multirow[t]{2}{*}{ Sex } & Men & 48.4 & 48.4 \\
\hline & Women & 51.6 & 51.6 \\
\hline \multirow[t]{3}{*}{ Age } & $18-34$ & 26.9 & 26.3 \\
\hline & $35-54$ & 36.5 & 37.7 \\
\hline & $55+$ & 36.1 & 36.0 \\
\hline \multirow[t]{3}{*}{ Education } & $\begin{array}{l}\text { Lower (primary and } \\
\text { lower secondary) }\end{array}$ & 21.9 & 20.2 \\
\hline & $\begin{array}{l}\text { Intermediate (higher } \\
\text { secondary) }\end{array}$ & 50.6 & 49.9 \\
\hline & Higher & 27.6 & 30.0 \\
\hline \multirow[t]{3}{*}{ Region } & Flanders & 58.4 & 58.4 \\
\hline & Brussels & 9.6 & 9.5 \\
\hline & Wallonia & 32 & 32.1 \\
\hline
\end{tabular}

for the reception stage of precrisis information processing.

\subsection{Description of the Data Collection and Sample}

The survey method employed in this study was computer assisted personal interviewing (CAPI), which entailed face-to-face interviews at the respondents' homes, the answers being directly recoded and stored on a portable hard disk. The survey was conducted by a professional market research company (Market Probe Belgium) on a large sample of the Belgian population $(N=1,031)$ in a chosen language (French or Dutch) in July and August 2009. A pilot study $(N=32)$ was performed and, based on the results, some modifications were made to improve the quality of the questionnaire. A stratified sample was applied to obtain a sample of respondents representative of the Belgian adult population with respect to the following variables: province, region, level of urbanization, gender, age, and professional status. Table II summarizes the characteristics of the sample. In this sample $(N=1,031)$, half of the respondents (519) remembered the campaign and they answered positively to the following question: "Some years ago, the authorities organized a distribution of iodine tablets as part of the nuclear emergency plan; do you know about the distribution of iodine tablets?"

The questionnaire was structured as a series of closed questions, most items having answering categories on a five-point Likert scale, with categories typically ranging from "strongly disagree" to 
"strongly agree." An additional "don't know/ no answer" option was allowed, but not encouraged.

\subsection{Model Variables: Measurements and Descriptive Analysis}

\subsubsection{Dependent Variable: Reception}

Reception was measured by the ability to recall the information, as suggested by Price and Zaller. Two analyses were carried out. For the first analysis, all respondents $(N=1,031)$ were asked a question related to the use of a stable iodine tablet in case of a nuclear accident: "In case of a nuclear accident, a stable iodine tablet would protect against... lung cancer/ bone cancer/skin burns/leukaemia/ thyroid cancer." A correct answer (thyroid cancer) was coded as 1, an incorrect one as 0 , and I don't know as 0 . Fifty-three percent of the respondents knew the correct answer.

In the second analysis, we selected the respondents who remembered the campaign $(N=519)$. In this way, it was possible to analyze the reception of specific messages from the campaign in depth. This subsample of respondents answered an additional set of four questions related to the campaign (see Appendix A). Among the people who were familiar with the iodine campaign, $53 \%$ were men and $47 \%$ were women, while $44 \%$ spoke French and 56\% spoke Dutch. In this respect, the subsample was similar to the representative sample for the Belgian population (in which $48 \%$ were men, $52 \%$ women, $42 \%$ French speaking, and 58\% Dutch speaking).

Dobrzynska and Blais ${ }^{(13)}$ and Price and Zaller ${ }^{(42)}$ measured reception by determining whether the respondents remembered a news story or political party orientation; if they did, they needed to give specific information connected to one particular aspect. In contrast to this method, we measured the reception of one story (communication-iodine campaign) using nine items in an exam-style format. This approach allowed us to gain an insight into what people recalled from the communication. The factor analysis carried out on these nine items identified a single dominant factor (Cronbach's $\alpha=0.64$ ), suggesting that the reception of precrisis communication is one-dimensional. For further analysis, the number of correct answers out of the nine items was used (see Appendix A). The values thus range from 0 to a maximum of 9 and form a scale for the reception of precrisis messages from the iodine campaign. Most of the people $(48 \%)$ who remembered the iodine campaign were able to recall six to eight messages from the campaign, and $4 \%$ were able to recall all messages $(M=5.4, S D=2.2$, Skewness $=-0.3)$. Only few ( $1 \%)$ stated that they remembered the iodine campaign, but were not able to recall any messages.

\subsubsection{Independent Variables}

Specific knowledge: In his model, Zaller ${ }^{(8)}$ recommended measuring specific knowledge by a simple test of specific factual information, while scholars in risk research ${ }^{(12,53,57)}$ have measured it as a selfreported item. In our study, specific knowledge was operationalized as the number of correct answers given to a set of 14 exam-style questions about protective actions in a nuclear emergency, the location of nuclear installations in Belgium, and nuclear technology (see Appendix B). The items measuring knowledge were not communicated during the campaign; thus knowledge can be treated as an independent variable. Since the purpose of the specific knowledge variable was to comprise different levels of knowledge, the items did not measure one latent construct. Responses were indexed, and the resulting absolute scale ranged from 0 to a maximum of 14 correct answers. While less than $1 \%$ of the respondents answered all 14 items correctly, most respondents had seven to 11 correct answers $(M=8, S D=2.9)$.

Experience with the hazard: Four questions on personal experience with the hazard were used in this survey (see Appendix C). The response was "yes" (1) or "no" (0) and the response "don't know" was recoded as a missing value. Hazard experience was calculated as a summation of the four recoded items $(M=0.5, S D=0.83)$. The results showed that the majority of the Belgian population (66\%) has no personal experience with nuclear technology or installations: about $5 \%$ have or had a job that involved radioactivity, about $12 \%$ have visited a nuclear installation, and the same percentage has close friends or relatives working in the field.

Confidence: Seven items were used to measure how much confidence the respondents have in the authorities for the actions they undertake to protect the population (see Appendix D). The answers ranged from "very low confidence" (1) to "very high confidence" (5). An exploratory factor analysis was performed using principal axis factoring and direct oblimin rotation. Only one scale was extracted with all seven items measuring confidence in the authorities to protect the population from radiation risks (Chronbach's $\alpha=0.87$ ). High scores on this scale 
Perko et al.

indicated a strong confidence in authorities. The factor scores were used as the independent variable measuring confidence.

Risk perception: Respondents were asked to evaluate the risks of seven different radiation risks for an ordinary Belgian citizen (see Appendix E). Responses ranged from "very low" (1) to "very high" (5). Two risk perception scales were extracted by factor analysis using principal axis factoring and direct oblimin rotation. The "risks related to the nuclear industry" referred to the perceived level of risk for an accident in a nuclear installation, radioactive waste, radioactivity in food, and a terrorist attack with a radioactive source (Chronbach's $\alpha=0.85$ ). "Risks unrelated to the nuclear industry" were medical X-rays, radiation from mobile phones, and natural radiation (Chronbach's $\alpha=0.63$ ). However, on this scale, the item related to X-rays had a lower loading than the other two items, which indicate that it may belong to a different construct. Low factor scores on both scales denoted a low perception of radiation risks. The factor scores for the two scales were used as independent variables.

Affective response (fear): Respondents' fear of an accident in a nuclear installation was measured by their level of agreement with the statement "An accident in a nuclear installation is strongly feared" on a five-point scale, ranging from 1 "strongly disagree" to 5 "strongly agree" $(M=4, S D=1.1)$.

\section{RESULTS}

\subsection{Bivariate Relationships}

We investigated the relationships between the reception measures and each of the following predictor variables: education (H1), specific knowledge $(\mathrm{H} 2)$, hazard experience $(\mathrm{H} 3)$, confidence $(\mathrm{H} 4)$, the perception of radiation risks unrelated to the nuclear industry (H5), the perception of radiation risks related to the nuclear industry (H5), and affective response (H6).

\subsubsection{Potential Predictors for Reception: The Complete Sample}

As introduced in the previous section, reception was first measured at the level of the whole population by one reception item "Recall of iodine tablets' purpose." The reception items were investigated separately for all predictor variables by logistic regression. Logistic regression for binary and multinomial
Table III. Predictors of Precrisis Communication Reception

\begin{tabular}{|c|c|c|}
\hline \multicolumn{3}{|c|}{ Model: Reception of Iodine Tablets' Purpose } \\
\hline Predictor & $\mathrm{B}$ & $S E$ \\
\hline \multicolumn{3}{|l|}{ Education } \\
\hline Primary & $-0.870^{*}$ & 0.423 \\
\hline Lower secondary & -0.686 & 0.366 \\
\hline Higher secondary & $-0.693 *$ & 0.343 \\
\hline Higher & -0.341 & 0.358 \\
\hline Specific knowledge & $0.255^{* * *}$ & 0.033 \\
\hline $\begin{array}{l}\text { Visited a nuclear power plant or } \\
\text { research reactor }\end{array}$ & -0.071 & 0.257 \\
\hline $\begin{array}{l}\text { Living or having lived close to a } \\
\text { nuclear installation }\end{array}$ & $-0.521^{*}$ & 0.213 \\
\hline $\begin{array}{l}\text { Had a job that involved the use of } \\
\text { radioactivity }\end{array}$ & -0.169 & 0.374 \\
\hline $\begin{array}{l}\text { Had a family member or close } \\
\text { friend with a job that involved } \\
\text { the use of radioactivity }\end{array}$ & -0.084 & 0.254 \\
\hline Confidence & $-0.179 *$ & 0.087 \\
\hline $\begin{array}{l}\text { Risk perception not industry } \\
\text { related radiation }\end{array}$ & $0.396 * * *$ & 0.114 \\
\hline $\begin{array}{l}\text { Risk perception industry related } \\
\text { radiation }\end{array}$ & $-0.339 * * *$ & 0.102 \\
\hline Affective response (fear) & -0.078 & 0.075 \\
\hline Constant & 0.570 & 0.963 \\
\hline $\begin{array}{l}N=758 \\
\text { Percentage correctly classified } 65 \\
\text { Nagelkerke pseudo- } R^{2}=0.20\end{array}$ & & \\
\hline
\end{tabular}

Note: Logistic regression analysis, dependent variables: Recall of iodine campaign, Recall of iodine tablets use: Yes $=1$ and $\mathrm{No}=0$. $* * * p<0.001 ; * * p<0.01 ; * p<0.05$.

outcomes is commonly used for binary and multinomial outcomes. ${ }^{(58)}$ The traditional coefficient of determination $R^{2}$ is not available for models with binary/multinomial outcome; instead, pseudo- $R^{2}$ statistics have been proposed, such as Nagelkerke's $R^{2}{ }^{2}{ }^{(59)}$ Although this measure has a similar proportional reduction of error interpretation, its maximum is usually not equal to 1 .

From Table III, we can conclude that, among the statistically significant predictors, specific knowledge and risk perception variables were most strongly related to recalling the purpose of the iodine tablets. The predictor risk perception of radiation risks was strongly related to the recall of iodine tablets' purpose. Respondents with less confidence in authorities for the actions taken to protect the population against radiation risks better recalled the campaign and the purpose of the iodine tablets than respondents with more confidence. The experience of living or having lived close to a nuclear installation had a statistically significant influence on 
reception. Education was only significant in the second regression model, related to the detailed recall of the purpose of iodine tablets; respondents with primary or higher secondary education were less likely to recall this message in comparison with respondents having a university degree. The regression model did not reveal a significant relationship between reception and group of respondents that "had a family member or close friend with a job that involved the use of radioactivity." The affective response was not significant for any reception item. However, the pseudo$R^{2}$ value of the model was moderately strong $\left(R^{2}=0.20\right)$.

\subsubsection{Potential Predictors for Reception: The Sample of People Remembering the Campaign}

We continued by investigating the relationships between the potential predictors and the ability to recall specific messages from the iodine distribution campaign. The reception index, calculated as a sum of the nine items measuring the recollection of the iodine distribution campaign, was used as the dependent variable. This was assumed to satisfy an interval level of measurement. For the scales corresponding to confidence, perception of risks related to the nuclear industry, and perception of risks unrelated to the nuclear industry, the factor scores were recalculated only for the respondents recalling the iodine distribution campaign. Linear regression was employed to study the influence of potential predictors, as stated in H1-H6 (see Table IV).

The regression analysis of the full model confirmed the previous results: the reception of communicated messages is mainly driven by specific knowledge. As reported in Table IV, specific knowledge was statistically significant and had the strongest regression coefficient $(\beta=0.35)$, up to three times larger than the ones obtained for the other statistically significant predictors.

Confidence and risk perception of the nuclear industry were revealed as significant, but risk perception had a negative $\beta$ coefficient $(-0,13)$. We expected people with a high perception of nuclear risks to be especially interested in receiving instructions about what to do in case of a nuclear accident. Hence, we assumed that these people would be interested to learn about iodine tablets and the information campaign (H5). However, the results showed exactly the opposite effect. A low recollection of information
Table IV. The Regression Models for Reception of Iodine Campaign Messages

Model: Reception of Iodine Campaign Messages

\begin{tabular}{lll}
\hline Predictor & $\beta$ & $S E$ \\
\hline Education & 0.055 & 0.358 \\
Specific knowledge & $0.348^{* * *}$ & 0.041 \\
Hazard experience & 0.035 & 0.103 \\
Confidence & $-0.125^{* *}$ & 0.109 \\
Perception of nuclear industry & & 0.123 \\
$\quad$ related radiation risks & 0.042 & 0.138 \\
Perception of nonnuclear industry & & \\
$\quad$ related radiation risks & -0.065 & 0.093 \\
Affective response (fear) & & 0.581 \\
Constant & & \\
\hline$N=447$ & & \\
$R^{2}($ adj) $=0.18$ & & \\
\hline
\end{tabular}

Note: Linear regression analysis, dependent variable: recall of iodine campaign messages.

*** $p<0.001 ; * * p<0.01 ; * p<0.05$.

was related to a high perception of radiation risks related to the nuclear industry.

We assumed that confidence in the authorities would influence attention to emergency communication in the preparedness phase, and that people with a higher degree of confidence would recall fewer messages (H4). Confidence was statistically significant as a predictor, but the influence is not in the expected direction. Respondents with a lot of confidence in the authorities were more likely to have high reception.

Education had a statistically significant, but weak, correlation (Spearman's rho $=0.114, p=$ 0.009 ) with reception of iodine campaign messages. A lower level of education was associated with a lower reception of information. However, education was not statistically significant as a predictor in the regression model.

Concerning hazard experience, we assumed that the recipients with hazard experience would be more likely to receive emergency messages in the preparedness phase of a nuclear emergency (H3). However, our results cannot confirm this expectation. The correlation between hazard experience and the recollection of preparedness communication was very weak (Spearman's rho $=0.094, p=0.032$ ); in addition, hazard experience was not a statistically significant predictor in the regression model. Still, we observed that more than half of the respondents $(66 \%)$ had no hazard experience. It is interesting to note that "living or having lived in an area close to a 
nuclear installation" as a separate item is not significantly correlated with the reception of messages from the information and the iodine distribution campaign (Sperman's rho $=0.044, p=0.252$ ).

The explanatory value of the full model was $18 \%$ of the variation in reception. The low variance explained by our model could potentially be further improved by inclusion of perceived benefits from intake of iodine tablets, as could be inferred from studies by, for example, Visschers et al. ${ }^{(60)}$

\section{DISCUSSION}

The goal of the present study was to investigate potential predictors and patterns in audience reception of precrisis risk communication and to empirically test whether the variables that have been traditionally used in risk research have an effect in the reception stage of information processing. Education, specific knowledge, confidence, risk perception, and affective response (fear) were assumed to be important at the reception level of information processing. By identifying the influence of systematic and heuristic predictors, we recognized the dominance of systematic predictors over heuristic ones at the reception level of information processing. We may conclude that those people who received and retained the messages successfully may possibly process the communicated information more deeply. This finding supports the theory of Petty and Cacioppo $^{(10)}$ that attitudes formed under high elaboration, the central route, are stronger than those formed under low elaboration.

People with plenty of specific knowledge were identified as especially attentive toward emergency preparedness communication, while people with high risk perception were mainly inattentive. However, the most important lesson from the study brings into attention the importance of specific knowledge: the communicated message may not be received if the audience has insufficient knowledge. If people do not possess a certain level of knowledge, the communicated messages will not trigger enough attention to be heard or recalled. In other words, hazards and risks have to be communicated openly and regularly long before a crisis in the context of preparedness for nuclear emergencies. For instance, information related to incidents (not only accidents) on a nuclear installation has to be publicly communicated.

Education was recognized as a rather weak predictor for the reception of precrisis communication. This result is similar to the studies from the field of political communication by Price et al.,${ }^{(42)}$ Zaller, ${ }^{(8)}$ and Dobrzynska and Blais. ${ }^{(13)}$ However, in risk research education is recognized as a predisposition for seeking out risk information and as an influencing factor for the extent to which a person will spend time and effort analyzing the risk information critically. ${ }^{(21)}$ In the risk-related literature, for example, the study of Griffin et al., (21) information processing is studied as a complete process, and reception and $a c$ ceptance are not separated as in our research. This may explain why in our research, education was not found to be a significant factor for the reception of information, as it could become more influential in the acceptance part of information processing. Moreover, risk communication related to iodine tablets was developed in a simple manner, using clear, short, and understandable messages. Thus, the education, which would probably enhance respondents' capacity to process risk-relevant information, was revealed as not significant. The hypothesis (H1) that the reception of pre-crisis messages is most accurate among people with a higher education level can be only partly accepted. It was confirmed that a lower education level is correlated with lower recollection of information.

In addition, the low correlation between education and specific knowledge (Spearman's rho $=0.197$, $p=0$ ) suggests that the information available in the education system or health communication programs related to specific knowledge about nuclear emergencies or the location of nuclear installations is insufficient. This is important for the development of preparedness communication, since people with more specific knowledge about the nuclear domain are more likely to receive nuclear emergency messages than people with less knowledge (H2). Therefore, it would be recommended to include more risk-related topics already in the education systems. These findings are in line with a recent theory that recognizes specific knowledge as a filter for information processing. ${ }^{(8,13,42)}$ The research on information gathering capacity by Griffin et al. ${ }^{(53)}$ confirms that the amount of knowledge people hold about a risk affects their capacity to gain new information about it. Moreover, our results suggest that people who are well-informed about the risk environment receive more information about emergency preparedness than people who do not know much about the risk. In other words, if people succeeded in understanding risk information in the past, this should enhance their ability to be attentive and to comprehend and retain risk information in the future. 
Risk has become a prevalent element in our daily life as we live in "a risk society."(19,61) Past experience may serve the individual as a guide for deciding how to think, behave, or react in a new situation, ${ }^{(43)}$ and it may trigger heuristic information processing. ${ }^{(7)}$ One of our research questions was to determine whether directly measured hazard experience becomes influential for the information processing at the reception stage. Our results showed that hazard experience did not have a significant influence on the reception of emergency preparedness communication (H3). It is interesting that hazard experience and specific knowledge did not correlate, meaning that people who have personal experience related to the nuclear domain do not always have a higher level of actual knowledge of the topic. In other words, living close to a nuclear installation or having visited a nuclear installation did not help people in gaining additional knowledge. This may be also due to the catastrophic potential of nuclear accidents, ${ }^{(62)}$ as risks arising from an accident in a nuclear installation are not limited to the vicinity of an installation.

The influence of confidence in the reception part of risk information processing is small. People's confidence in the authorities to protect the population against radiation risks has a weak influence on the attention they pay to emergency communication in the preparedness phase (H4). It might, however, become influential later on in the information processing. For instance, recent research by Whitfield ${ }^{(63: 425)}$ suggests that "increased trust in the nuclear governance institutions reduces the perceived risk of nuclear power and together higher trust and lower nuclear risk perception predict positive attitudes toward nuclear power." However, current literature suggests that risk regulators have problems with the low level of public trust and accordingly they face difficulties in mobilizing the necessary social support for nuclear activities or decision making. In most cases, the public assesses regulators on the basis of their past decisions. ${ }^{(2)}$ Our research showed that people with a lot of confidence in the authorities receive more nuclear emergency information. From this point of view, it is important for risk communicators to learn that people with low levels of confidence will be more resistant to even notice the communicated information, let alone accept it.

Perception of risk in the literature is usually studied as a dependent variable, to provide an insight into how people respond to specific characteristics of various risks. ${ }^{(64)}$ In our research though, risk perception is used as an independent variable, as a potential (heuristic) predictor of reception. Our hypothesis was that people with a higher perception of nuclear risks will receive more nuclear emergency messages (H5). The relationship between risk perception and reception indeed appeared to be statistically significant. However, linear regression revealed a low explanatory power of this predictor for the reception of detailed communication messages. Contrary to our expectations, a high perception of radiation risks related to the nuclear industry was negatively correlated with the recollection of information about iodine tablets. This might be explained based on previous risk perception research ${ }^{(2,22,65)}$ and media research, ${ }^{(66)}$ according to which risk perception is lower for familiar/known risks. In other words, people's familiarity or ability to personalize a media topic increases people's degree of attentiveness to communicated messages related to these risks, and thus it stimulates reception. Moreover, precrisis communication has to be designed for people having high risk perception, since they seem to have a lower reception of preparedness-related information. In general, public understanding of nuclear risk-related information is hindered by the complexity of the risk concept. This concept includes not only the probability and consequences of a nuclear event, but also the specific risk characteristics. ${ }^{(22)}$ For nuclear hazards such characteristics are, among others, the strong link to the high catastrophic potential, fear, and unfamiliarity. ${ }^{(65)}$ These and other characteristics of the nuclear risk have to be addressed by risk communicators.

A growing body of research indicates that emotional reactions and moods influence information processing. ${ }^{(21,39,53)}$ We investigated if fear as a measurement of an affective response influences the reception stage of processing. The results of our empirical testing indicated that fear of an accident at a nuclear installation did not predict the respondent's reception of precrisis information related to protection measures (H6).

\section{CONCLUSION}

To conclude, this study showed that heuristic predictors have a limited influence in the reception stage of information processing. Among the information processing predictors studied, specific knowledge plays a dominant role in the reception of precrisis communication. People with plenty of specific knowledge were identified as particularly attentive, motivated, and able to recollect the 
information related to nuclear emergency preparedness communication. Education, hazard experience, confidence, risk perception, and affective response (fear) - although statistically significant—do not play an important role in the reception of precrisis information. The findings plead for long-term riskcommunication campaigns, for instance, involvement in the education system. In communication strategies, a special attention has to be dedicated to a group of people with high risk perception, since this limits the attention to risk-related information.

In formulating the conclusions of this study, certain limitations must be recognized. First, in light of the rather low explained variances, some factors might be missing in the explanatory model. For instance, the respondents could be perceiving the effectiveness of taking iodine tablets during a nuclear incident as rather limited. This is also related to the choice of taking this protective action as a case in point for nuclear emergency preparedness. The distribution of the tablets took place seven years before the start of the study, so that the respondents had to dig deep into their memory. Still, it turned out to be an appropriate choice given the objectives of the study. Unfortunately, it was not possible for this study to take the possible effects of the Fukushima nuclear accident into account. This is a missed opportunity. A second limitation relates to the operationalization of some key variables, such as reception and prior knowledge. In the limited space of the questionnaire, it was not possible either to go into great detail on all facets of prior knowledge regarding nuclear power, or to include comprehensive attitude measurements. Nevertheless, a large and representative sample was obtained. Moreover, by using professional interviewers, the reliability of the collected data can be regarded as quite high, so that the generalizability of the conclusions is less open to question than is often the case in small-scale experimental research.

Future research will need to address the acceptance part of information processing. It is likely that in this part, heuristic predictors prove to be more influential than systematic ones. Finally, further research on crisis and postcrisis (recovery) communication would also be advisable.

\section{ACKNOWLEDGMENTS}

The field work for data collection was funded through the R\&D collaboration agreement between SCK•CEN and GdF-SUEZ.

\section{APPENDIX A: RECEPTION OF COMMUNICATED MESSAGES}

\begin{tabular}{|c|c|c|c|}
\hline $\begin{array}{l}\text { Reception of Preparedness } \\
\text { Communication-Iodine } \\
\text { Campaign }\end{array}$ & Correct Answer & $\begin{array}{c}1^{\text {st }} \text { Analysis } \\
\% \text { of Correct Answers } \\
\text { (from } N=1,031) \\
\alpha \text { Depend.Var. }=0.85\end{array}$ & $\begin{array}{c}2^{\text {nd }} \text { Analysis } \\
\% \text { of Correct Answers } \\
(\text { from } N=519) \\
\alpha \text { Depend.Var. }=0.64\end{array}$ \\
\hline \multicolumn{4}{|l|}{$\begin{array}{l}\text { A stable iodine tablet would protect } \\
\text { against: }\end{array}$} \\
\hline ... lung cancer & No & 41 & 54 \\
\hline$\ldots$ bone cancer & No & 43 & 53 \\
\hline ... skin burns & No & 51 & 67 \\
\hline ... leukaemia & No & 38 & 48 \\
\hline ... thyroid cancer & Yes & 53 & 68 \\
\hline $\begin{array}{l}\text { Do you know about the distribution } \\
\text { of iodine tablets? }\end{array}$ & Yes / I have heard something about it & 50 & 100 \\
\hline $\begin{array}{l}\text { Do you know who was invited to } \\
\text { collect these iodine tablets? }\end{array}$ & $\begin{array}{l}\text { The people living in the radius of } 20 \\
\mathrm{~km} \text { of a nuclear installation }\end{array}$ & NA & 71 \\
\hline $\begin{array}{l}\text { In case of nuclear alarm, should you } \\
\text { take the tablets immediately or } \\
\text { should you wait }\end{array}$ & Wait for instructions & NA & 54 \\
\hline $\begin{array}{l}\text { Where can you get these iodine } \\
\text { tablets? }\end{array}$ & At the local pharmacy & NA & 69 \\
\hline $\begin{array}{l}\text { Are these iodine tablets free or to be } \\
\text { paid for? }\end{array}$ & Free & NA & 53 \\
\hline
\end{tabular}




\section{APPENDIX B: SPECIFIC KNOWLEDGE}

\begin{tabular}{|c|c|c|}
\hline $\begin{array}{l}\text { Specific Knowledge Scale } \\
N=1,031\end{array}$ & $\begin{array}{l}\text { Correct } \\
\text { Answer }\end{array}$ & $\begin{array}{l}\% \text { of Correct } \\
\text { Answers }\end{array}$ \\
\hline \multicolumn{3}{|l|}{$\begin{array}{l}\text { Indicate whether the following } \\
\text { towns have a nuclear power } \\
\text { plant: }\end{array}$} \\
\hline Hasselt & No & 65 \\
\hline Lier & No & 63 \\
\hline Liege & No & 54 \\
\hline Doel & Yes & 70 \\
\hline Tihange & Yes & 73 \\
\hline $\begin{array}{l}\text { Is a radiological dispersal device (also } \\
\text { known as dirty bomb) the same as an } \\
\text { atomic bomb? }\end{array}$ & No & 47 \\
\hline $\begin{array}{l}\text { Will exposure to radiation necessarily } \\
\text { lead to a contamination with } \\
\text { radioactive material? }\end{array}$ & No & 26 \\
\hline $\begin{array}{l}\text { Which percentage of electric power } \\
\text { in Belgium is produced in nuclear } \\
\text { plants? }\end{array}$ & $\begin{array}{l}\text { Between } \\
45-65 \%\end{array}$ & 29 \\
\hline \multicolumn{3}{|l|}{$\begin{array}{l}\text { Which of the following sectors make use } \\
\text { of nuclear technology: }\end{array}$} \\
\hline Production of electricity & Yes & 95 \\
\hline Medical sector & Yes & 87 \\
\hline Food industry & Yes & 25 \\
\hline Textile industry & Yes & 50 \\
\hline $\begin{array}{l}\text { Belgium has decided to phase out nuclear } \\
\text { energy. }\end{array}$ & Yes & 43 \\
\hline $\begin{array}{l}\text { There exists a plan to ensure the } \\
\text { protection of the population in case of } \\
\text { a nuclear accident. }\end{array}$ & Yes & 71 \\
\hline
\end{tabular}

\section{APPENDIX C: HAZARD EXPERIENCE}

\begin{tabular}{|c|c|}
\hline Alpha $=0.50, N=1,031$ & $\begin{array}{l}\% \text { of } \\
\text { Respondents Having } \\
\text { This Experience }\end{array}$ \\
\hline $\begin{array}{l}\text { Had a job that involved the use } \\
\text { of radioactivity (nuclear } \\
\text { power plant, industry, or } \\
\text { hospital using the } \\
\text { radioactive sources, ....) }\end{array}$ & 5 \\
\hline $\begin{array}{l}\text { Had a family member or close } \\
\text { friend with a job that } \\
\text { involved the use of } \\
\text { radioactivity }\end{array}$ & 12 \\
\hline $\begin{array}{l}\text { Visited a nuclear power plant } \\
\text { or research reactor }\end{array}$ & 13 \\
\hline $\begin{array}{l}\text { Lived in an area close (within a } \\
\text { 20-km radius) to a nuclear } \\
\text { installation (power plant, } \\
\text { nuclear research } \\
\text { institute ...) }\end{array}$ & 20 \\
\hline
\end{tabular}

\section{APPENDIX D: FACTOR LOADINGS AND OTHER SCALES ATTRIBUTES FOR CONFIDENCE}

\begin{tabular}{lcccc}
\hline $\begin{array}{l}\text { Confidence in } \\
\text { Authorities for } \\
\text { the Actions Undertaken }\end{array}$ & $\begin{array}{c}\text { Factor } \\
\text { Loading } \\
\text { Principal } \\
\text { Axainst Radiation Risks }\end{array}$ & $\begin{array}{c}\text { CFA } \\
\text { Loadings }\end{array}$ & $\begin{array}{c}\text { Alphat } \\
\text { of } 1,031\end{array}$ \\
\hline Radioactivity in food & 0.799 & 0.83 & & \\
$\begin{array}{l}\text { Accident nuclear } \\
\text { installation }\end{array}$ & 0.725 & 0.77 & & \\
$\quad$ Radioactive waste & 0.714 & 0.74 & & \\
$\quad \begin{array}{l}\text { Natural radiation } \\
\text { Terrorist attack radioactive }\end{array}$ & 0.700 & 0.76 & 0.87 & 835 \\
$\quad$ source & 0.698 & 0.75 & & \\
Medical X-rays & 0.668 & 0.72 & & \\
Radiation GSM & 0.593 & 0.75 & & \\
\hline
\end{tabular}

\section{APPENDIX E: FACTOR LOADINGS AND OTHER SCALES ATTRIBUTES FOR RADIATION RISKS}

\begin{tabular}{|c|c|c|c|c|}
\hline $\begin{array}{l}\text { Perception of } \\
\text { Nuclear-Industry- } \\
\text { Related Radiation Risks }\end{array}$ & $\begin{array}{l}\text { Factor } \\
\text { Loading } \\
\text { Principal } \\
\text { Axis }\end{array}$ & $\begin{array}{c}\text { CFA } \\
\text { Loadings }\end{array}$ & Alpha & $\begin{array}{c}N \text { out } \\
\text { of } 1,031\end{array}$ \\
\hline $\begin{array}{l}\text { Accident nuclear } \\
\text { installation }\end{array}$ & 0.849 & 0.83 & \multirow{4}{*}{0.85} & \multirow{4}{*}{958} \\
\hline Radioactive waste & 0.804 & 0.80 & & \\
\hline Radioactivity in food & 0.715 & 0.77 & & \\
\hline $\begin{array}{l}\text { Terrorist attack radioactive } \\
\text { source }\end{array}$ & 0.704 & 0.77 & & \\
\hline $\begin{array}{l}\text { Perception of non-nuclear- } \\
\text { industry-related } \\
\text { radiation risks }\end{array}$ & $\begin{array}{l}\text { Factor } \\
\text { Loading } \\
\text { Principal } \\
\text { axis }\end{array}$ & $\begin{array}{c}\text { CFA } \\
\text { Loadings }\end{array}$ & Alpha & $\begin{array}{c}N \text { out } \\
\text { of } 1,031\end{array}$ \\
\hline Medical X-rays & 0.621 & 0.49 & \multirow{3}{*}{0.63} & \multirow{3}{*}{912} \\
\hline Radiation GSM & 0.569 & 0.40 & & \\
\hline Natural radiation & 0.454 & 0.92 & & \\
\hline
\end{tabular}

\section{REFERENCES}

1. Van Bladel L, Pauwels A, Smeesters P. The challenge of interacting with the public on nuclear emergency preparedness and iodine prophylaxis. Pp. 141-147 in OECD-NEA Workshop Investing in Trust: Nuclear Regulators and the Public. Paris, France: OECD, 2000.

2. Renn O. Risk governance; coping with uncertainty in a complex world. In Lofstedt RE (ed). Earthscan Risk in Society Series. London: Earthscan, 2008.

3. Lang A. The limited capacity model of mediated message processing. Journal of Communication, 2000; 50(1):46-70. 
4. Chaiken S, Stangor C. Attitudes and attitude change. Annual Review of Psychology, 1987; 38:575-630.

5. Ohman A. As fast as the blink of an eye: Evolutionary preparedness for preattentive processing of threat. Pp. 165-184 in Proceedings of the Conference in Honor of Frances Keesler Graham-Attention and Orienting: Sensory and Motivational Processes, Oct. Atlanta, GA: Lawrence Erlbaum Assoc. Pub., 1994.

6. Visschers V, Meertens RM, Passchier WW, de Vries NN. Probability information in risk communication: A review of the research literature. Risk Analysis, 2009; 29(2): 267-287.

7. Trumbo WC. Information processing and risk perception: An adaption of the heuristic-systematic model. Journal of Communication, 2002; 52:367-382.

8. Zaller J. The Nature and Origins of Mass Opinion. New York: Cambridge University Press, 2006.

9. Price V, Zaller J. Who gets the news-Alternative measures of news reception and their implications for research. Pp. 133164 in Meeting of the American Political Science Assoc, 1990. San Francisco, CA, 1993.

10. Petty ER, Cacioppo JT. The elaboration likehood model of persuasion. Pp. 124-192 in Berkowitz AD (trans and ed). Advances in Experimental Social Psychology, Vol. 19. New York: Academic Press, 1986.

11. Jooyoung K, Hye-Jin P. Information processing of genetically modified food messages under different motives: An adaptation of the multiple-motive heuristic-systematic model. Risk Analysis, 2009; 29(12):1793-1806.

12. Huurne E, Griffin RJ, Gutteling JM. Risk information seeking among US and Dutch residents: An application of the model of risk information seeking and processing. Science Communication, 2009; 31:215-237.

13. Dobrzynska A, Blais A. Testing Zaller's reception and acceptance model in an intense election campaign. Political Behaviour, 2007; 30:259-276.

14. Dalton RJ, Beck PA, Huckfeldt R. Partisan cues and the media: Information flows in the 1992 presidential election. Pp. 111-126 in American Political Science Review. San Francisco, CA: American Political Science Association, 1996.

15. IEA. Manual for first responders to a radiological emergency. In IAE Agency (ed). Emergency Preparedness and Response. Series manual for first responders to a radiological emergency. Vienna, 2006.

16. Eurobarometer. Europeans and nuclear safety. In EC (ed). Special Eurobarometer 297 Series Europeans and Nuclear safety. Brussels: European Commission, 2007.

17. Eurobarometer. Attitudes Towards radioactive waste. In Series Attitudes Towards radioactive waste, Vol. 297. Brussels: European Commission, 2008.

18. Blando JD, Robertson C, Bresnitz E. Communicating information in an emergency preparedness pill distribution campaign. Biosecurity and Bioterrorism-Biodefense Strategy Practice and Science, 2008; 6(1):57-65.

19. Beck U. Living in the world risk society. Economy and Society, 2006; 35(3):329-345.

20. Jones B, Baumgartner F. The Politics of Attention. How Government Prioritizes Attention. Chicago: University of Chicago Press, 2005.

21. Griffin RJ, Dunwoody S, Neuwirth K. Proposed model of the relationship of risk information seeking and processing to the development of preventive behaviors. Environmental Research, 1999; A80:230-245.

22. Slovic P, Finucane ML, Peters E, MacGregor DG. Risk as analysis and risk as feelings: Some thoughts about affect, reason, risk, and rationality. Risk Analysis, 2004; 24(2): 311-322.
23. Sjöberg L. Myths of the psychometric paradigm and how they can misinform risk communication. Report No.: 2006:10. Stockholm: Center for Risk Research, 2006.

24. Eagly AH. Uneven progress-Social psychology and the study of attitudes. Journal of Personality and Social Psychology, 1992; 63(5):693-710.

25. Lang A, Bolls P, Potter RF, Kawahara K. The effects of production pacing and arousing content on the information processing of television messages. Journal of Broadcasting \& Electronic Media, 1999; 43(4):451-475.

26. Lang A. Using the limited capacity model of motivated mediated message processing to design effective cancer communication messages. Journal of Communication, 2006; 56:S57-S80.

27. Shiffrin RM, Schneider W. Automatic and controlled processing revisited. Psychological Review, 1984; 91(2):269-276.

28. Eysenck MW, Keane MT. Cognitive Psychology, 5th ed. London: Psychology Press, 2005.

29. McGuire WJ (ed). Persuasion, Resistance, and Attitude Change. Chicago, IL: Rand McNally, 1973.

30. Eagly AH, Chaiken S. The Psychology of Attitudes. Harcourt, Brace Jovanovich College Publishers, 1993.

31. Tversky A, Kahneman D. Judgement under uncertaintyHeuristics and biases. Science, 1974; 185:1124-1131.

32. Visschers VHM, Meertens RM, DeVries KN. How does the general public evaluate risk information? The impact of associations with other risks. Risk Analysis, 2007; 27(3): $715-727$.

33. Earle TC, Cvetkovich GT. Social Trust: Toward a Cosmopoli$\tan$ Society. Westpoint, CT: Praeger, 1995.

34. Freudenburg WR. Risk and recreancy-Weber, the division of labour and the rationality of risk perception. Social Forces, 1993; 71(4):909-932.

35. Kasperson JX, Kasperson E. R. The Social Contours of Risk. Virginia: Earthscan, 2005.

36. Slovic P. The Perception of Risk. London: Earthscan Publications, 2000.

37. Siegrist M, Cvetkovich G, Roth C. Salient value similarity, social trust, and risk/benefit perception. Risk Analysis, 2000; 20(3):311-322.

38. Loewenstein GF, Weber UE, Hsee CK, Welch N. Risk as feelings. Psychological Bulletin, 2001; 127:267-286.

39. Bohner G, Apostolidou W. Mood and persuasionIndepandent effects of affect before and after message processing. Journal of Social Psychology, 1994; 134(5):707709.

40. Jepson C, Chaiken S. Chronic issue-specific fear inhibits systematic processing of persuasive communications. Journal of Social Behavior and Personality, 1990; 5(2):61-84.

41. Griffin RJ. Energy in the eighties: Education, communication and the knowledge gap. Journalism \& Mass Communication Quarterly, 1990; 67:554-566.

42. Price V, Zaller J. Who gets the news? Alternative measures of news reception and their implications for research. Public Opinion Quarterly, 1993; 57:133-164.

43. Grunig JE. Communication behaviors and attitudes of environmental publics: Two studies. Journalism Monographs, 1983; 81:1-47.

44. Johnson EJ, Tversky A. Affect, generalization, and the perception of risk. Journal of Personality and Social Psychology, 1983; 45(1):20-31.

45. Siegrist M, Cvetkovich G, Roth C. Salient value similarity, social trust, and risk/benefit perception. Risk Analysis, 2000; 20(3):353-362.

46. Ibitayo OO, Pijawka KD. Reversing NIMBY: An assessment of state strategies for siting hazardous-waste facilities. Environment and Planning C-Government and Policy, 1999; 17(4):379-389. 
47. Slovic P, Flynn JH, Layman M. Perceived risk, trust and the politics or nuclear waste. Science, 1991; 254(5038):1603-1607.

48. Sjöberg L. Local acceptance of a high-level nuclear waste repository. Risk Analysis, 2004; 24(3):737-749.

49. Earle TC, Siegrist M. Morality information, performance information and the distinctionbetween trust and confidence. Journal of Applied Social Psychology, 2006; 36(2):383-416.

50. Gaskell G, Allum N, Wagner W, Kronberger N, Torgersen H, Hampel J, et al. GM foods and the misperception of risk perception. Risk Analysis, 2004; 24(1):185-194.

51. Dake K. Myths of nature-Culture and the social construction of risk. Journal of Social Issues, 1992; 48(4):21-37.

52. Fischhoff B, Slovic P, Lichtenstein S, Read S, Combs B. How safe is safe enough-Psychometric study of attitudes towards technological risks and benefits. Policy Sciences, 1978; 9(2): $127-152$.

53. Griffin RJ, Yang J, Huurne E. After the flood: Anger, attribution, and the seeking of information. Science Communication, 2008; 29:285-315.

54. Bohner G, Chaiken S, Hunyadi P. The role of mood and message ambiguity in the interplay of heuristic and systamatic processing. European Journal of Social Psychology, 1994; 24(1):207-221.

55. Jourdain JR, Herviou K, Bertrand R, Clemente M, Petry A. Medical Effectiveness of Iodine Prophylaxis in a Nuclear Reactor Emergency Situation and Overview of European Practices. Report No.: 1337. France: RISKAUDIT IRSN/GRS International.
56. Belgian Federal Crisis Centre. Efficacité des comprimés. d'iode confirmée. Available at: http://www.crisiscentrum.be/ index.php?option $=$ com_content $\&$ task $=$ view $\&$ id $=257 \&$ Itemid=1. 2010 end., Series Efficacité des comprimés d'iode confirmée Ministry of internal affairs; 2010.

57. Kahlor LA, Dunwoody S, Griffin RJ, Neuwirth K. Seeking and processing information about impersonal risk. Science Communication, 2006; 28:163-194.

58. Menard S. Applied Logistic Regression. London: Sage, 2001.

59. Bo H, Jun S, Mari P. Pseudo $R^{2}$ in logistic regression model. Statistica Sinica, 2006; 16:847-860.

60. Visschers VHM, Keller C, Siegrist M. Climate change benefits and energy supply benefits as determinants of acceptance of nuclear power stations: Investigating an explanatory model. Energy Policy, 2011; 39:3621-3629.

61. Beck U. The Risk Society: Toward a New Modernity. London, UK: Sage, 1992.

62. Slovic P. Perception of risk from radiation. Radiation Protection Dosimetry, 1996; 68(3/4):165-180.

63. Whitfield SC, Rosa EA, Dan A, Dietz T. The future of nuclear power: Value orientations and risk perception. Risk Analysis, 2009; 29(3):425-437.

64. Kasperson RE, Renn O, Slovic P, Brown HS, Emel J, Goble R, Kasperson J X, Ratick S. The social amplification of riskA conceptual framework. Risk Analysis, 1988; 8(2):177-187.

65. Sjöberg L. Are received risk perception models alive and well? Risk Analysis, 2002; 22(4):665-669.

66. Clark V, Harvey R. Media Studies. Longman, 2002. 